\title{
Effect of the supernatant reflux position and ratio on the nitrogen removal performance of anaerobic-aerobic slaughterhouse wastewater treatment process
}

\author{
Shuang Tong ${ }^{1,2^{\dagger}}$, Yan Zhao ${ }^{1,2}$, Ming Zhu ${ }^{1,2}$, Jing Wei ${ }^{1,2}$, Shaoxiang Zhang ${ }^{3}$, Shujie $\mathrm{Li}^{4}$, \\ Shengdan Sun $^{3}$ \\ ${ }^{1}$ Beijing Key Laboratory of Meat Processing Technology, China Meat Research Center, Beijing 100068, China \\ ${ }^{2}$ Beijing Academy of Food Sciences, Beijing 100068, China \\ ${ }^{3}$ School of Water Resources and Environment, China University of Geosciences Beijing, Beijing 100083, China \\ ${ }^{4}$ School of Civil and Architectural Engineering, Liaoning University of Technology, Jinzhou 121001, Liaoning, China
}

\begin{abstract}
Slaughterhouse wastewater (SWW) is characterized as one of the most harmful agriculture and food industrial wastewaters due to its high organic content. The emissions of SWW would cause eutrophication of surface water and pollution of groundwater. This study developed a pilot scale anaerobic-aerobic slaughterhouse wastewater treatment process (AASWWTP) to enhance the chemical oxygen demand (COD) and total nitrogen (TN) removal. The optimum supernatant reflux position and ratio for TN removal were investigated through the modified Box-Behnken design (BBD) experiments. Results showed that COD could be effectively reduced over the whole modified BBD study and the removal efficiency was all higher than $98 \%$. The optimum reflux position and ratio were suggested to be 2 alure and $100 \%$, respectively, where effluent TN concentration was satisfied with the forthcoming Chinese discharge standard of $25 \mathrm{mg} / \mathrm{L}$. Anaerobic digestion and ammonia oxidation were considered as the main approaches for COD and TN removal in the AASWWTP. The results of inorganic nutrients $\left(\mathrm{K}^{+}, \mathrm{Na}^{+}, \mathrm{Ca}^{2+}\right.$ and $\left.\mathrm{Mg}^{2+}\right)$ indicated that the SWW was suitable for biological treatment and the correspondingly processes such as AASWWTP should be widely researched and popularized. Therefore, AASWWTP is a promising technology for SWW treatment but more research is needed to further improve the operating efficiency.
\end{abstract}

Keywords: Enhanced nitrogen removal, Modified Box-Behnken design (BBD), Partial denitrification (PD)-ANAMMOX, Slaughterhouse wastewater (SWW) treatment, SWW treatment processes comparison

\section{Introduction}

The global production of meat is projected to progressively grow until 2050 [1], which will represent an expected increase in the amount of slaughterhouse wastewater (SWW) requiring treatment [2]. SWW is characterized as one of the most harmful agriculture and food industrial wastewaters due to its high organic content [3]. The emissions of SWW would cause eutrophication of surface water and pollution of groundwater [4] due to its high organic carbon and nitrogen $(\mathrm{N})$ compounds [5].

Chinese meat production has been consistently ranked the first

This is an Open Access article distributed under the term of the Creative Commons Attribution Non-Commercial License (http://creativecommons.org/licenses/by-nc/3.0/) which permits unrestricted non-commercial use, distribution, and reproduction in any medium, provided the original work is properly cited.

Copyright (C) 2020 Korean Society of Environmental Engineers place in the world since 1990. Unlike other countries, pork is the most consumed meat in China, which accounted for $63.6 \%$ of the total meat production [6]. Correspondingly, "Effluent standard of pollutants for meat processing industry (GB 13457-92)" was firstly established in the last century, which is updating in line with the enhancement for water environmental protection in China (000014672/2018-01201). In which, effluent limit of total nitrogen (TN) has been added. The permitted maximum concentration of effluent TN has been set at 25, 20, and $15 \mathrm{mg} / \mathrm{L}$ for enterprises that are existed, new-built, and in environmental sensitive areas, respectively.
Received February 14, 2019 Accepted April 29, 2019

$\dagger$ Corresponding author

Email: selina_wen@foxmail.com

Tel: +86-10-67264755 Fax: +86-10-87293157

ORCID: 0000-0002-4623-4908 
Chemical oxygen demand (COD) and ammonia nitrogen $\left(\mathrm{NH}_{4}{ }^{+}-\mathrm{N}\right)$ were the main concern contaminants in the previous lab and case studies. Combined anaerobic-aerobic processes were developed to reduce the corresponding COD and $\mathrm{NH}_{4}{ }^{+}$as well as cost maintenance [1]. Alure-type wastewater treatment process (ATWTP) was firstly proposed in recent decades [7], which was improved as the enhanced alure-type biological system (E-ATBS) to enhance the biological nutrient removal and got the excellent performance [6]. However, E-ATBS has the very long processes, which would bring higher costs and staff requirements.

Consequently, the design of experiments (DOEs) is widely used to surpass the limitations of traditional experimental methods in terms of time, materials and the number of experimental trials $[1,8]$. DOEs include central composite designs, Doehlert matrixes, and Box-Behnken designs (BBDs) [9], in which BBDs need the least runs to investigate per variation. DOEs have been employed successfully to optimize the operational parameters in wastewater treatment $[1,8,10]$.

In this study, the E-ATBS was bravely shorted to the anaerobic-aerobic SWW treatment process (AASWWTP) in the light of the characteristics of SWW, which was consist of five-stage ABR and only one-stage biological contact oxidation (BCO) tank. A pilot scale AASWWTP was installed to investigate its COD, $\mathrm{NH}_{4}{ }^{+}-\mathrm{N}$ and TN removal capacities. Therefore, the overall goal of this research was to investigate the applicability and removal and economic efficiencies of the developed AASWWTP. The specific objectives were to: (1) investigate the COD, $\mathrm{NH}_{4}{ }^{+}-\mathrm{N}$ and $\mathrm{TN}$ removal capacities of AASWWTP at different conditions designed through the modified BBD; (2) investigate the influence of the supernatant reflux position and ratio on the TN removal performance; (3) evaluate and summarize the operating mechanism of AASWWTP; and (4) compare the TN removal performance and economic efficiency of AASWWTP with other published biological SWW treatment processes.

\section{Materials and Methods}

\subsection{Experimental Set-up}

The flowchart of the AASWWTP is shown in Fig. 1. AASWWTP consist of regulating tank (RT), ABR with four anaerobic alures (1A, 2A, 3A and 4A) and one anoxic alure (5A), BCO tank and clarifier successively.

The acrylic bioreactor contained one $108 \mathrm{~L} \mathrm{ABR}$ reactor (23.4, 22.5, 21.6, 20.7 and 19.8 L for 1A, 2A, 3A, 4A and 5A, respectively) and one 24.0 L BCO reactor. The soft combined semi-soft packing filter was used in the BCO reactor as the microbial attachment. The structure of the packing filter was a double-ring large plastic ring, on which were pressed the aldehyde fibers and in which was fixed by the snowflake plastic branch (Fig. 1). The packing filter diameter was $100 \mathrm{~mm}$. The spacing was $80 \mathrm{~mm}$. The packing filter was connected in series through the central fiber rope. A composite packing filter with the total folding length of $3 \mathrm{~m}$ was placed in the whole BCO reactor.

\subsection{SWW Composition}

Synthetic SWW was prepared according to the real wastewater, which has been discussed in the previous study [6]. Synthetic SWW was prepared aimed to contain 2,000 $\pm 100 \mathrm{mg} / \mathrm{L}$ of COD and $160 \pm 10 \mathrm{mg} / \mathrm{L}$ of TN by adding the fresh porcine blood and sodium citrate. Note that sodium citrate was not only used to adjust the $\mathrm{C} / \mathrm{N}$, but also to avoid the blood coagulation.

\subsection{Experimental Design}

In this study, modified version design method according to BBD was applied to optimize the supernatant reflux position and ratio. According to the previous study [6] and the AASWWTP designed operation mode, the 2-4 anaerobic alures of ABR was chosen as the supernatant reflux position together with 100\%-300\% supernatant reflux ratios. Table 1 shows the modified BBD experiment including two variations and three levels. In this table, the independent variable levels were presented in terms of the coded levels. The coded values set for reflux position (A) and ratio (B) at three levels were: $-1,0,+1$. The reflux positions were set at compartment 2, 3 and 4, and reflux ratios were 100\%, 200\% and $300 \%$, respectively. Note that the minimum number of experimental runs was needed (only 5 runs in this study) through introducing the modified BBD, which is worth popularized.

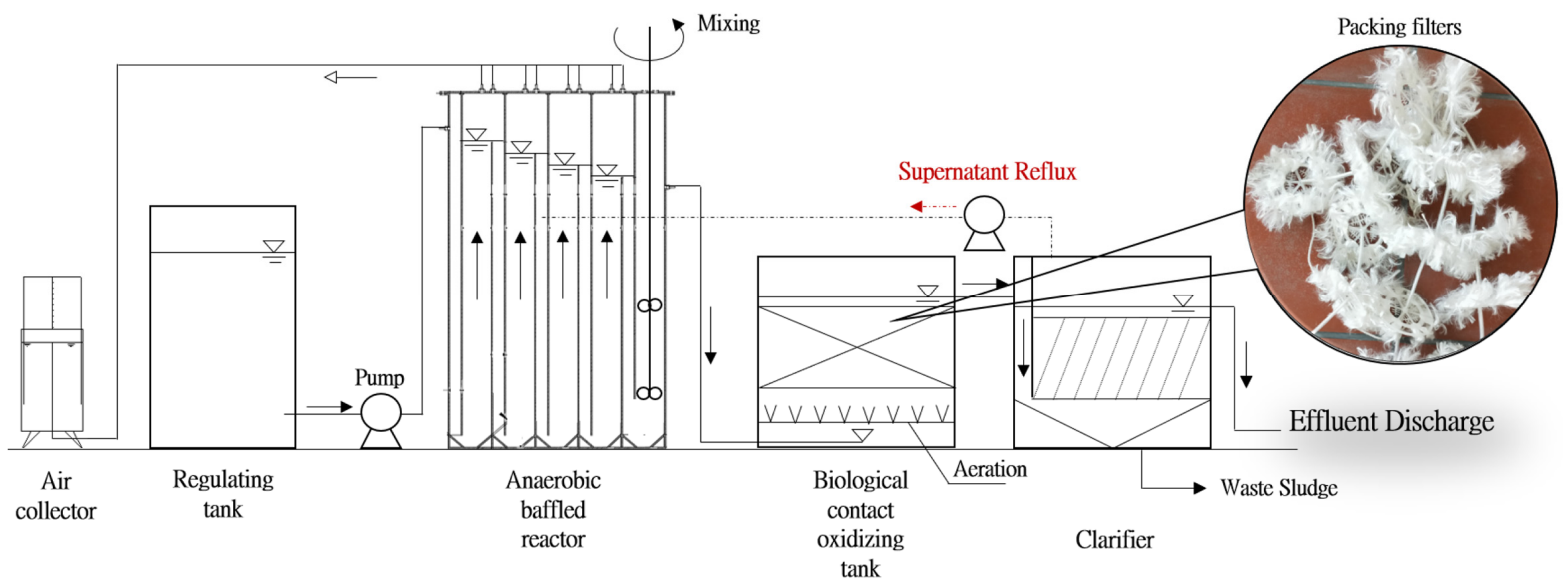

Fig. 1. Flowchart of anaerobic-aerobic slaughterhouse wastewater treatment process (AASWWTP). 
Table 1. Design for the Study of Two Experimental Variables, Reflux Position and Ratio

\begin{tabular}{|c|c|c|c|c|}
\hline \multirow{2}{*}{$\begin{array}{l}\text { Run } \\
\text { No. }\end{array}$} & \multicolumn{2}{|c|}{ Factor A: Reflux position } & \multicolumn{2}{|c|}{ Factor B: Reflux ratio } \\
\hline & Code & Actual compartment & Code & Actual value \\
\hline R1 & -1 & 2 & -1 & $100 \%$ \\
\hline $\mathrm{R} 2$ & -1 & 2 & +1 & $300 \%$ \\
\hline R3 & 0 & 3 & 0 & $200 \%$ \\
\hline $\mathrm{R} 4$ & +1 & 4 & -1 & $100 \%$ \\
\hline R5 & +1 & 4 & +1 & $300 \%$ \\
\hline
\end{tabular}

To obtain the appropriate reflux position and ratio, six dependent parameters were analysed: $\mathrm{COD}, \mathrm{TN}, \mathrm{NH}_{4}{ }^{+}-\mathrm{N}, \mathrm{NO}_{2}{ }^{-}-\mathrm{N}, \mathrm{NO}_{3}{ }^{-}-\mathrm{N}$ and $\mathrm{pH}$.

\subsection{Experimental Procedures}

\subsubsection{Experimental start-up}

The inoculums were taken from the corresponding anaerobic, anoxic and aerobic tanks of slaughterhouse wastewater treatment plant in the previous case study [6]. Seed sludge was acclimated in the developed AASWWTP bioreactor for $30 \mathrm{~d}$ in the continuous mode with the pollution load of $500 \mathrm{~g} \mathrm{COD} / \mathrm{m}^{3} / \mathrm{d}$ and run at room temperature of $20 \pm 2^{\circ} \mathrm{C}$. The bioreactor was considered as start-up successfully when the effluent COD was kept lees than $80 \mathrm{mg} / \mathrm{L}$, which was the effluent limit in the online draft of "Effluent standard of pollutants for slaughter and meat processing industry" (000014672/2018-01201).

\subsubsection{Experimental run}

To determine the appropriate supernatant reflux position and ratio, the AASWWTP bioreactor was run according to the modified BBD in Table 1. Two parallel samples for effluent were taken every $24 \mathrm{~h}$. When the effluent COD and TN concentrations were stable (a $p$-value with a 95\% confidence level; [11]), two parallel samples for influent, effluent and at different compartments were taken and analysis for COD, TN, $\mathrm{NH}_{4}{ }^{+}-\mathrm{N}, \mathrm{NO}_{2}^{-}-\mathrm{N}, \mathrm{NO}_{3}^{-}-\mathrm{N}$ and $\mathrm{pH}$. Experiments were repeated if there was a sample analysis error greater than $5 \%$.

The inorganic nutrients of $\mathrm{K}^{+}, \mathrm{Na}^{+}, \mathrm{Ca}^{2+}$ and $\mathrm{Mg}^{2+}$ for microbial growth at the optimum TN removal condition was also detected to investigate the nutrient supply of SWW to microorganisms.

\subsection{Analytical Methods}

Water samples were taken from each stage and then filtered by $0.45 \mu \mathrm{m}$ membrane before detection except for COD and TN. $\mathrm{NH}_{4}{ }^{+}-\mathrm{N}, \mathrm{NO}_{2}{ }^{-}-\mathrm{N}$, and $\mathrm{NO}_{3}{ }^{-}-\mathrm{N}$ were measured using a spectrophotometer (DR6000, HACH, USA) according to the Chinese NEPA [12] standard methods, and the method detection limits (MDLs) were $0.035,0.003$ and $0.052 \mathrm{mg} / \mathrm{L}$, respectively. $\mathrm{K}^{+}, \mathrm{Na}^{+}, \mathrm{Ca}^{2+}$ and $\mathrm{Mg}^{2+}$ were measured using a Metrohm ECO Compact IC Pro (Herisau, Switzerland) ion chromatograph. MDLs were 0.07, 0.13, 0.07 and $0.07 \mathrm{mg} / \mathrm{L}$ for $\mathrm{K}^{+}, \mathrm{Na}^{+}, \mathrm{Ca}^{2+}$ and $\mathrm{Mg}^{2+}$, respectively.

COD was measured through Lovibond mid-range kits with the MDL of $0-1,500 \mathrm{mg} / \mathrm{L}$. TN concentration was measured using Hach TNT plus 827 test kit. $\mathrm{pH}$ was measured using a $\mathrm{pH}$ meter with calibrated electrode (FiveEosy Plus, Mettler Toledo, Switzerland; MDL: 0-14).

\section{Results and Discussion}

\subsection{COD Removal}

Average COD concentration and COD removal efficiency in each modified BBD study are shown in Fig. 2. COD was removed successively with the flow of SWW in the AASWWTP bioreactor. Moreover, the reflux position also played an important role in

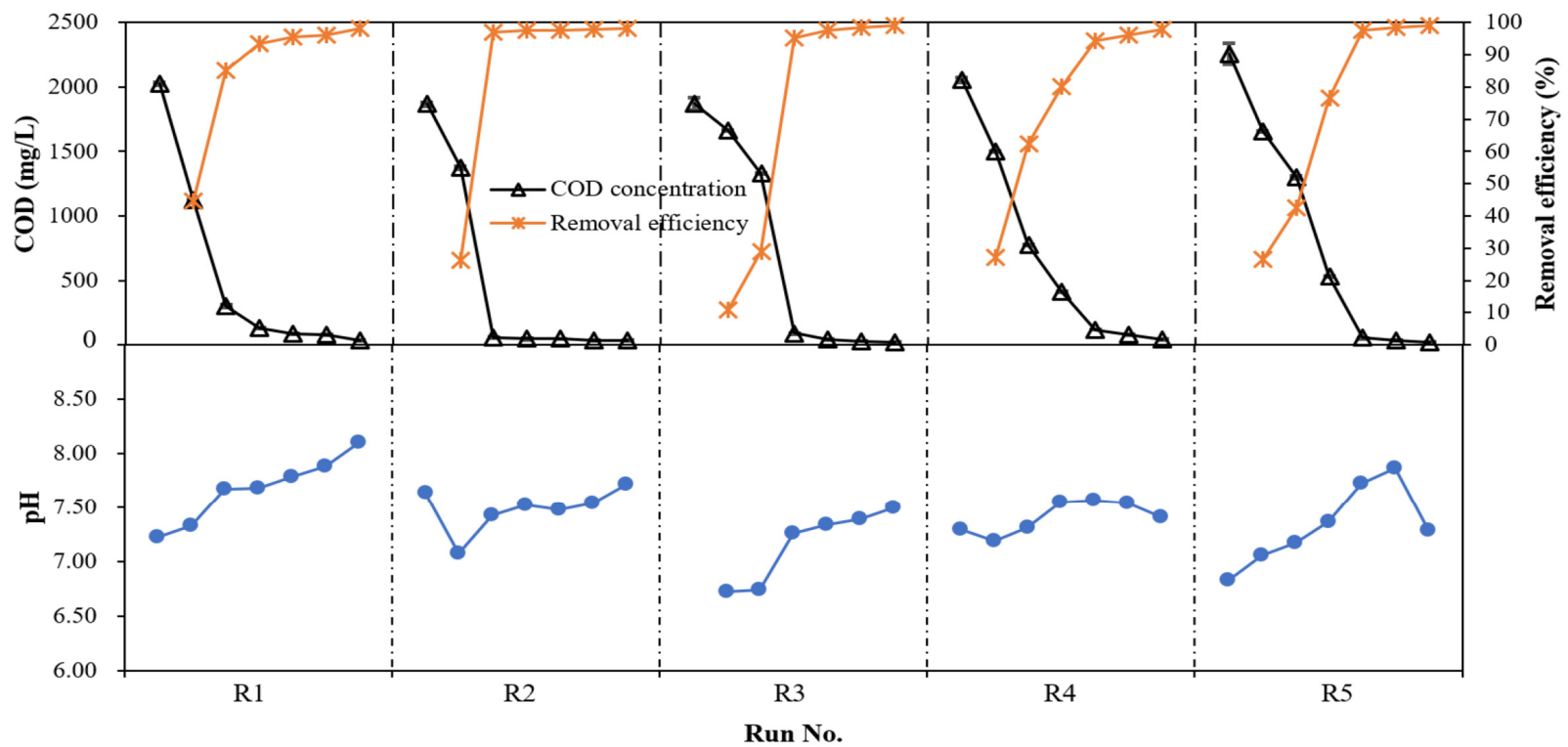

Fig. 2. Average of COD concentration, removal efficiency and $\mathrm{pH}$ level in each design study. The stages were influent from regulating tank, $1 \mathrm{~A}, 2 \mathrm{~A}, 3 \mathrm{~A}, 4 \mathrm{~A}, 5 \mathrm{~A}$ and effluent successively. 
COD removal. For example, when the supernatant returned into the second compartment of $\mathrm{ABR}, \sim 50 \% \mathrm{COD}$ was removed in this compartment.

From Fig. 2, it could be also found that all effluent COD concentrations were between $19 \pm 1$ and $43 \pm 3 \mathrm{mg} / \mathrm{L}$, which were much lower than the Chinese SWW discharge standard of 80 $\mathrm{mg} / \mathrm{L}$. COD removal efficiency was all higher than 98\%, which was much higher than $80 \%$ of previous ATWTP [7] and similar to the upgraded enhanced alure-type biological system (E-ATBS) [6]. Hence, it could be concluded that the supernatant reflux can guarantee the efficient COD removal without adding more structures.

As known, discharge standard of $\mathrm{pH}$ was 6.00-9.00, which also reflected the suitable $\mathrm{pH}$ condition microbial growth [13]. In this study, $\mathrm{pH}$ at each modified BBD condition and each stage was all satisfied the above condition. However, the $\mathrm{pH}$ at each stage in the AASWWTP bioreactor showed the different trend at different modified BBD conditions. The supernatant reflux position and ratio affected the $\mathrm{pH}$ level simultaneously. This might be due to the introduced reflux affecting the microbial reactions of $\mathrm{N}$ removal, which would be fully described in section 3.2.

\subsection{Nitrogen Removal}

Average concentrations of $\mathrm{NH}_{4}{ }^{+}-\mathrm{N}, \mathrm{NO}_{2}{ }^{-}-\mathrm{N}, \mathrm{NO}_{3}{ }^{-}-\mathrm{N}$, TN and $\mathrm{TN}$ removal efficiency in each designed study are shown in Fig. 3. $\mathrm{NH}_{4}{ }^{+}-\mathrm{N}$ and organic $\mathrm{N}$ formed the main contaminates of TN in SWW. Organic $\mathrm{N}$ firstly digested to $\mathrm{NH}_{4}{ }^{+} \mathrm{N}$ in the anaerobic stage. As shown in Fig. 3, $\mathrm{NH}_{4}{ }^{+}-\mathrm{N}$ concentration increased most obviously in the first anaerobic stage of $\mathrm{ABR}(1 \mathrm{~A})$, which was also demonstrated that $1 \mathrm{~A}$ played the roles of both hydrolysis-acidification and anaerobic digestion for organic matter simultaneously. $\mathrm{NH}_{4}{ }^{+}$ accumulated continuously until the supernatant returned compartment/alure and then decreased sharply at the corresponding alure due to partial denitrification (PD)-ANAMMOX [6]. After this alure, $\mathrm{NH}_{4}{ }^{+}-\mathrm{N}$ concentration increased again slowly as the remainder organic $\mathrm{N}$ amination in the rest of ABR. Finally, $\mathrm{NH}_{4}{ }^{+}-\mathrm{N}$ concentration decreased to lower than $0.50 \mathrm{mg} / \mathrm{L}$ at the aerobic stage of BCO reactor.

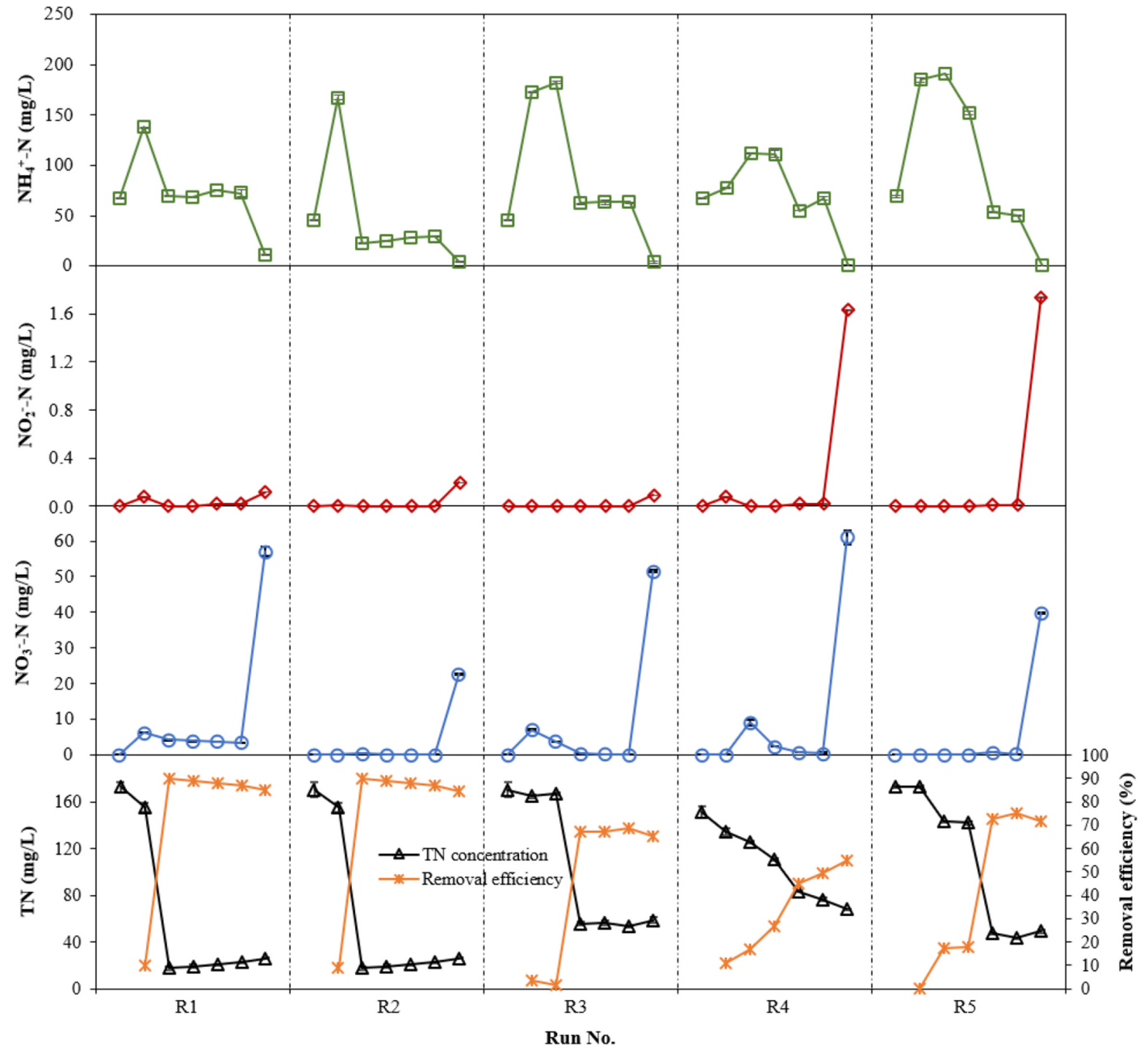

Fig. 3. Average of $N$ species and $T N$ removal efficiency in each design study. The stages were influent from regulating tank, $1 A, 2 A, 3 A, 4 A$, $5 \mathrm{~A}$ and effluent successively. 
$\mathrm{NO}_{2}^{-}$and $\mathrm{NO}_{3}^{-}$as the nitrification productions can be used as the source for PD-ANAMMOX [14]. However, different reflux conditions would lead to different amount of $\mathrm{NO}_{2}{ }^{-}$and $\mathrm{NO}_{3}{ }^{-}$accumulations in the final effluent. In this study, the highest $\mathrm{NO}_{2}^{-}-\mathrm{N}$ and $\mathrm{NO}_{3}{ }^{-} \mathrm{N}$ accumulation of $1.74 \pm 0.01$ and $61.00 \pm 1.98 \mathrm{mg} / \mathrm{L}$ were detected at the conditions of R5 and R4, respectively. Hence, the supernatant returned to the forth compartment/alure would lead to the highest $\mathrm{NO}_{2}^{-}$and $\mathrm{NO}_{3}^{-}$by-products accumulation. The more forward the supernatant reflux position was, the lower $\mathrm{NO}_{2}{ }^{-}$ and $\mathrm{NO}_{3}{ }^{-}$by-products accumulation would be gained. At the same time, it could be found that $\mathrm{NO}_{3}{ }^{-} \mathrm{N}$ concentration in effluent was lowest at $22.62 \pm 0.28 \mathrm{mg} / \mathrm{L}$ at the condition of R2 (reflux position at 2 alure and ratio of $300 \%$ ).

As shown in Fig. 3, $\mathrm{NO}_{2}^{-}-\mathrm{N}$ concentration through the whole anaerobic and anoxic stages in ABR was all lower than $0.02 \mathrm{mg} / \mathrm{L}$. Correspondingly, $\mathrm{NO}_{3}{ }^{-} \mathrm{N}$ concentration was lower than $10 \mathrm{mg} / \mathrm{L}$. Unlike $\mathrm{NO}_{2}^{-}, \mathrm{NO}_{3}^{-}-\mathrm{N}$ concentration increased obviously at the reflux compartment/alure. This also can be used as the side validation of the analysis of PD-ANAMMOX as the main process for TN removal in the AASWWTP.

TN decreased slowly except for the supernatant reflux compartment/alure, which was similar to the COD removal in ABR but decreased more sharply. The supernatant reflux introduced the $\mathrm{NO}_{2}^{-}$and $\mathrm{NO}_{3}^{-}$as well as small amount of dissolved oxygen (DO), leading to the occurrence of PD-ANAMMOX [6]. In which, $\mathrm{NO}_{2}{ }^{-}$ accumulated from partial nitrification in BCO reactor could be used together with the accumulated $\mathrm{NH}_{4}{ }^{+}$in $\mathrm{ABR}$ for the ANAMMOX firstly as description in Eq. (1) [14]. After the supernatant reflux compartment, TN began to slowly increase except for R4, which was absolutely different to COD removal trend. Further study is needed as to analyse the microorganisms to find out the bacteria that lead to this slow increase.

$$
\begin{aligned}
& \mathrm{NH}_{4}^{+}+1.32 \mathrm{NO}_{2}^{-}+0.066 \mathrm{HCO}_{3}^{-}+0.13 \mathrm{H}^{+} \\
& \rightarrow 1.02 \mathrm{~N}_{2}+0.26 \mathrm{NO}_{3}^{-}+0.066 \mathrm{CH}_{2} \mathrm{O}_{0.5} \mathrm{~N}_{0.15}+2.03 \mathrm{H}_{2} \mathrm{O}
\end{aligned}
$$

Meanwhile, the reflux $\mathrm{NO}_{3}^{-}$from $\mathrm{BCO}$ reactor and the produced $\mathrm{NO}_{3}{ }^{-}$from ANAMMOX process were used as the electron acceptor for microbial denitrification. As known, $\mathrm{NO}_{3}{ }^{-}$was the preferred electron acceptor over $\mathrm{NO}_{2}^{-}$in microbial denitrification, expressed as $\mathrm{NO}_{3}{ }^{-} \rightarrow \mathrm{NO}_{2}^{-} \rightarrow \mathrm{N}_{2}$ [15]. Hence, the intermediate product of $\mathrm{NO}_{2}{ }^{-}$ would be accumulated during the PD process and be used as the reactant for ANAMMOX, forming the PD-ANAMMOX process to advanced TN removal. Moreover, some $\mathrm{NO}_{3}{ }^{-}$would be remained through the PD-ANAMMOX process according to Eq. (1), which was consist with the modified BBD experiment results. Almost all $\mathrm{NH}_{4}^{+}$and $\mathrm{NO}_{2}^{-}$were removed and only some $\mathrm{NO}_{3}^{-}$was accumulated at the conditions of R1, R2 and R3 (reflux position at 2 or 3 alure).

Effluent TN concentrations at R1 and R2 were the same as lowest level of $25 \mathrm{mg} / \mathrm{L}$, which was satisfied with the Chinese SWW discharge standard for the existing enterprises. As known, lots of existing enterprises in China use the combined anaerobic-aerobic processes to reduce COD and $\mathrm{NH}_{4}{ }^{+}$from SWW to match the existing "Effluent standard of pollutants for meat processing industry (GB 13457-92)" [6]. Hence, according to this study, it could be concluded that only the addition of supernatant reflux would lead to the objective of TN decrease. The existing enterprises can improve the SWW treatment plant only through the simple modification, which can use the minimum cost and ensure the effluent satisfied with the upcoming discharge standard.

Through the analysis of $\mathrm{NH}_{4}{ }^{+}-\mathrm{N}, \mathrm{NO}_{2}^{-}-\mathrm{N}, \mathrm{NO}_{3}{ }^{-}-\mathrm{N}$ and $\mathrm{TN}$ in the AASWWTP bioreactor at different design studies, it could be concluded that both $\mathrm{R} 1$ and $\mathrm{R} 2$ showed the excellent $\mathrm{N}$ removal capacity. Considering that the increase of reflux ratio would increase the operation cost, R1 (reflux position at 2 alure and ratio of $100 \%$ ) was chosen as the optimum condition for $\mathrm{N}$ removal in AASWWTP. However, the further study is still need to optimate the supernatant reflux conditions more precisely.

\subsection{Inorganic Nutrients Characteristics}

$\mathrm{K}^{+}, \mathrm{Na}^{+}, \mathrm{Ca}^{2+}$ and $\mathrm{Mg}^{2+}$ as the main inorganic nutrients for microbial growth had also been detected in the optimum condition of reflux position at 2 alure and ratio of 100\% (Fig. 4). As shown in Fig. 4, there is enough inorganic nutrients of $\mathrm{K}^{+}, \mathrm{Na}^{+}, \mathrm{Ca}^{2+}$ and $\mathrm{Mg}^{2+}$ in the synthesized SWW. But only $\mathrm{Ca}^{2+}$ decreased a little during the AASWWTP, whereas $\mathrm{K}^{+}, \mathrm{Na}^{+}$, and $\mathrm{Mg}^{2+}$ concentrations increased. This might be due to the inorganic nutrient utilization by microorganisms lower than the nutrient mineralization from porcine blood. As known, $\mathrm{K}^{+}, \mathrm{Na}^{+}, \mathrm{Ca}^{2+}$ and $\mathrm{Mg}^{2+}$ contents in the fresh porcine blood were $56,56,4$, and $5 \mathrm{mg} / 100 \mathrm{~g}$, respectively [16]. In which $\mathrm{Ca}^{2+}$ content was the lowest. Hence, only $\mathrm{Ca}^{2+}$ showed the decreased trend during the SWW treatment. Moreover, $\mathrm{Na}^{+}$increased most obviously as the co-containing in the fresh porcine blood and sodium citrate. These results also indicate that the SWW is suitable for biological treatment and the correspondingly processes such as AASWWTP should be widely researched and popularized.

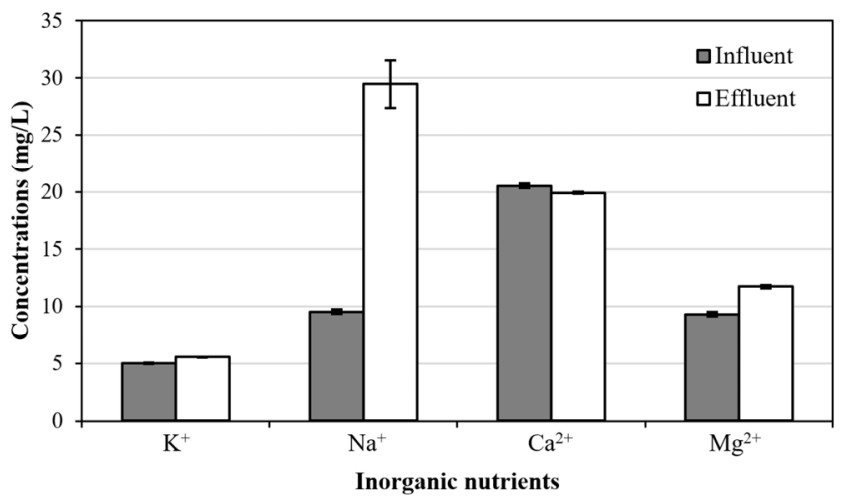

Fig. 4. Inorganic nutrients variation at the optimum condition of reflux position at 2 alure and ratio of $100 \%$.

\subsection{SWW Treatment Processes Comparison}

Reducing COD and BOD concentrations in SWW is the main focus of the secondary biological treatment by removing soluble organic compounds at the beginning of lab and case studies [17]. However, $\mathrm{N}$ species in SWW would cause eutrophication of surface water and pollution of groundwater if SWW emissions without fully treatment [4]. Hence, biological nitrogen removal (BNR) process has been added together with COD removal in the secondary bio- 
Table 2. Comparison of Different Biological Technologies for SWW Treatment

\begin{tabular}{|c|c|c|c|c|c|c|c|}
\hline Published year & Processes $^{\mathrm{a}}$ & Types $^{b}$ & Feed & $\begin{array}{c}\text { HRT }^{\mathrm{c}} \\
\mathbf{h}\end{array}$ & \multicolumn{2}{|c|}{$\begin{array}{cc}\text { Influent TN } & \text { TN removal efficiency } \\
\mathrm{mg} / \mathrm{L} & \%\end{array}$} & References \\
\hline 2005 & FFR & Ana-Ae & $2-3 \mathrm{~N} \mathrm{~m}^{3} / \mathrm{h}$ & $23-91$ & $150-260$ & 69.0 & [19] \\
\hline 2006 & ABR-CSTR & Ana-Ae & 0.3-3.16 kg COD $/ \mathrm{m}^{3} / \mathrm{d}$ & 249 & $70-147$ & 77.4 & [20] \\
\hline 2007 & UASB & Ana & $1.6 \pm 0.4 \mathrm{~kg} \mathrm{COD} / \mathrm{m}^{3} / \mathrm{d}$ & 69 & $147-233$ & $36.0-40.0$ & [21] \\
\hline 2009 & ASR-Lagoon & Ae-Ano/Ana & $1,500 \mathrm{~m}^{3} / \mathrm{d}$ & 10 & $78-457$ & $52.0-93.0$ & [22] \\
\hline 2011 & $\mathrm{~A}^{2} \mathrm{O}$ & Ana-Ano-Ae & $15 \mathrm{~L} / \mathrm{d}$ & 16 & $84-409$ & 81.5-95.6 & {$[23]$} \\
\hline 2013 & UASB-AFBR & Ana-Ae & - & 24 & 169 & 76.0 & {$[24]$} \\
\hline 2014 & SBR & Ano-Ana-Ano & $0.6 \mathrm{~L} / \mathrm{min}$ & $12-16$ & $143-175$ & 80.8-91.1 & [25] \\
\hline 2017 & ABR-ASR & Ana-Ae & $63 \mathrm{~mL} / \mathrm{min}$ & - & 161-255 & 72.1 & {$[1]$} \\
\hline 2019 & E-ATBS & Ana-Ae-Ano-Ae- & $700-900 \mathrm{~m}^{3} / \mathrm{d}$ & - & $115-211$ & $>90.8$ & {$[6]$} \\
\hline This study & AASWWTP & Ana-Ae & $25 \mathrm{~L} / \mathrm{d}$ & 96 & $150-170$ & 84.9 & - \\
\hline
\end{tabular}

${ }^{\mathrm{a}}$ FFR: Fixed-film reactors; CSTR: Completely stirred tank reactor; UASB: Upflow anaerobic sludge blanket reactor; ASR: Activated sludge reactor; $\mathrm{A}^{2} \mathrm{O}$ : Anaerobic/anoxic/oxic system; AFBR: Aerated fixed-bed reactor; SBR: Sequencing batch reactor

${ }^{\mathrm{b}}$ Ana: Anaerobic; Ano: Anoxic; Ae: Aerobic

${ }^{\mathrm{c}}$ HRT: Hydraulic retention time

logical treatment processes. The biological processes for removing $\mathrm{N}$ species from wastewaters mainly included tradition nitrification/denitrification process, SHARON process $\left(\mathrm{NH}_{4}{ }^{+}\right.$is oxidized only to $\mathrm{NO}_{2}^{-}$followed by denitrification), and ANAMMOX process [18].

Table 2 illustrates some published biological processes for TN removal from SWW in this century. There are lots of different and combined biological technologies used in SWW treatment. It could be concluded that combination biological processes and integrated systems always showed better TN removal efficiency. As shown in Table 2, Del Nery et al. used the simple anaerobic technology of UASB and got the TN removal efficiency of $36.0 \%-40.0 \%$ [21]. Other published technologies in Table 2 all used the combined biological technologies and got higher TN removal efficiencies, which were ranged from $52.0 \%$ to $95.6 \%$.

Comparing to other published technologies, the AASWWTP showed relatively high TN removal efficiency, but not the highest. Considering the effluent standard of SWW in China, the developed AASWWTP was able to fit its requirement for effluent TN. In the previous study, the E-ATBS in case study has been fully discussed and showed the TN removal efficiency as high as $98 \%$ [6]. However, the E-ATBS contained much longer biological processes as hydrolysis-acidification tank (HT), anaerobic tank (1A) with 3 compartments, oxic tank 1 (1O1), oxic tank 2 (1O2), anoxic tank (2A), oxic tank (2O), clarifier, and sand filter successively. However, the AASWWTP developed in this study only had the shared anaerobic and anoxic tank of ABR and oxic tank of BCO. Comparing of AASWWTP and E-ATBS, the developed AASWWTP can reduce about $30 \%-40 \%$ cost through the following four aspects: (1) the number of oxic tank reduced from three to one, which would save about 33\% electricity consumption for aeration; but the supernatant reflux would consume about $5 \%$ from that saving. (2) The reduced structures would save about 30\%-40\% land occupation; (3) the disposable cost for construction would save about $30 \%-40 \%$ simultaneously; and (4) less operating and maintenance costs were needed. Hence, on the basis of ensuring the effective removal of TN, the developed AASWWTP can greatly reduce the cost of capital investment and operation and maintenance. AASWWTP is a promising technology for TN removal from SWW. Further scientific calculation would be done in the next step study to confirm the accurate budget.

In addition, the combined biological and physicochemical processes have also been studied and utilized in the advanced $\mathrm{N}$ removal of SWW. Bohdziewicz and Sroka reported the combined activated sludge (AS)-reverse osmosis (RO) system for the treatment of SWW and gained a high COD and TN removal of $99.80 \%$ and $99.77 \%$, respectively [26]. Bustillo-Lecompte et al. [27] developed a combined ABR-AS-UV/ $\mathrm{H}_{2} \mathrm{O}_{2}$ process and reported up to $99.98 \%$ TOC and $82.84 \%$ TN removal efficiencies.

Although combined biological and physicochemical methods often got the high removal efficiencies, the simple biological processes were still gotten priority in the practical application considering to the relatively low operating costs, low requirements for operators and the environment friendly. Moreover, the development of biological processes also ensured the high TN removal efficiency. The developed AASWWTP in this study got the $85 \%$ TN removal efficiency, which showed a litter higher than the combined biological and physicochemical method of ABR-AS-UV $/ \mathrm{H}_{2} \mathrm{O}_{2}$ ( $\left.283 \%\right)$ [27]. Hence, the biological processes for SWW treatment should be widely researched and popularized.

\section{Conclusions}

AASWWTP for advanced TN removal of SWW was developed and the optimum supernatant reflux position and ratio were investigated. COD could be effectively reduced over the whole modified BBD study and the removal efficiency was all higher than $98 \%$. The optimum reflux position and ratio were suggested to be 2 alure and 100\%, respectively. Effluent TN concentration was satisfied with the upcoming Chinese discharge standard for the existing enterprises of $25 \mathrm{mg} / \mathrm{L}$. AASWWTP is a promising 
technology for SWW treatment but more research is needed to further improve the operating efficiency.

\section{Acknowledgments}

This research was financially supported by China Postdoctoral Science Foundation (Grant No. 2018M630245), the National Key Research and Development Program of China (Grant No. 2016YFD0501405) and Beijing Postdoctoral Research Foundation (Grant No. 2017-ZZ-137). The authors would like to thank the local slaughterhouse industry for the supply of seed sludge and fresh porcine blood.

\section{References}

1. Bustillo-Lecompte CF, Mehrvar M. Treatment of actual slaughterhouse wastewater by combined anaerobic-aerobic processes for biogas generation and removal of organics and nutrients: An optimization study towards a cleaner production in the meat processing industry. J. Clean. Prod. 2017;141:278-289.

2. Bustillo-Lecompte CF, Mehrvar M. Treatment of an actual slaughterhouse wastewater by integration of biological and advanced oxidation processes: Modeling, optimization, and cost-effectiveness analysis. J. Environ. Manage. 2016;182:651-666.

3. Palatsi J, Viñas M, Guivernau M, Fernandez B, Flotats X. Anaerobic digestion of slaughterhouse waste: Main process limitations and microbial community interactions. Bioresour. Technol. 2011;102:2219-2227.

4. USEPA. Effluent limitations guidelines and new source performance standards for the meat and poultry products point source category. United States Environmental Protection Agency (USEPA) Federation Registration; 2004.

5. Tritt WP, Kang H. Slaughterhouse wastewater treatment in a bamboo ring anaerobic fixed-bed reactor. Environ. Eng. Res. 2018;23:70-75.

6. Tong S, Wang S, Zhao Y, Feng C, Xu B, Zhu M. Enhanced alure-type biological system (E-ATBS) for carbon, nitrogen and phosphorus removal from slaughterhouse wastewater: A case study. Bioresour. Technol. 2019;274:244-251.

7. Zhao X, Xu Z, Wang S. Effect factors of soy sauce wastewater treatment by allure-type wastewater treatment equipment. Energ. Procedia 2012;16:65-69.

8. Tong S, Chen N, Wang $\mathrm{H}$, et al. Optimization of $\mathrm{C} / \mathrm{N}$ and current density in a heterotrophic/ biofilm-electrode autotrophic denitrification reactor (HAD-BER). Bioresour. Technol. 2014;171:389-395.

9. Bingöl D, Veli S, Zor S, Özdemir U. Analysis of adsorption of reactive azo dye onto $\mathrm{CuCl}_{2}$ doped polyaniline using Box-Behnken design approach. Synth. Met. 2012;162:1566-1571.

10. Tong S, Rodriguez-Gonzalez LC, Payne KA, Stocks JL, Feng C, Ergas SJ. Effect of pyrite pretreatment, particle size, dose, and biomass concentration on particulate pyrite autotrophic denitrification of nitrified domestic wastewater. Environ. Eng. Sci. 2018;35:875-886.

11. Tong S, Stocks JL, Rodriguez-Gonzalez LC, Feng C, Ergas SJ.
Effect of oyster shell medium and organic substrate on the performance of a particulate pyrite autotrophic denitrification (PPAD) process. Bioresour. Technol. 2017;244:296-303.

12. NEPA. Water and wastewater monitoring analysis method. 4th ed. Beijing: China Environmental Science Press; 2002.

13. Oh SE, Yoo YB, Young JC, Kim IS. Effect of organics on sulfur-utilizing autotrophic denitrification under mixotrophic conditions. J. Biotechnol. 2001;92:1-8.

14. Du R, Cao S, Wang S, Niu M, Peng Y. Performance of partial denitrification (PD)-ANAMMOX process in simultaneously treating nitrate and low $\mathrm{C} / \mathrm{N}$ domestic wastewater at low temperature. Bioresour. Technol. 2016;219:420-429.

15. Glass C, Silverstein J. Denitrification kinetics of high nitrate concentration water: $\mathrm{pH}$ effect on inhibition and nitrite accumulation. Water Res. 1998;32:831-839.

16. Yingyang.00cha.com. Nutritional label of porcine blood [Internet]. c2012 [cited 10 April 2019]. Available from: http://yingyang.00cha.com/NzA2.html (in Chinese).

17. Pierson JA, Pavlostathis SG. Real-time monitoring and control of sequencing batch reactors for secondary treatment of a poultry processing wastewater. Water Environ. Res. 2000;72:585-592.

18. McCarty PL. What is the best biological process for nitrogen removal: When and why? Environ. Sci. Technol. 2018;52:3835-3841.

19. Del Pozo R, Diez V. Integrated anaerobic-aerobic fixed-film reactor for slaughterhouse wastewater treatment. Water Res. 2005;39:1114-1122.

20. Kuşçu OS, Sponza DT. Treatment efficiencies of a sequential anaerobic baffled reactor (ABR)/completely stirred tank reactor (CSTR) system at increasing p-nitrophenol and COD loading rates. Process Biochem. 2006;41:1484-1492.

21. Del Nery V, de Nardi IR, Damianovic MHRZ, Pozzi E, Amorim AKB, Zaiat M. Long-term operating performance of a poultry slaughterhouse wastewater treatment plant. Resour. Conserv. Recy. 2007;50:102-114.

22. Kist LT, Moutaqi SE, Machado ÊL. Cleaner production in the management of water use at a poultry slaughterhouse of Vale do Taquari, Brazil: A case study. J. Clean. Prod. 2009;17:1200-1205.

23. Fongsatitkul P, Wareham DG, Elefsiniotis P, Charoensuk P. Treatment of a slaughterhouse wastewater: Effect of internal recycle rate on chemical oxygen demand, total Kjeldahl nitrogen and total phosphorus removal. Environ. Technol. 2011;32:1755-1759.

24. Barana AC, Lopes DD, Martins TH, et al. Nitrogen and organic matter removal in an intermittently aerated fixed-bed reactor for post-treatment of anaerobic effluent from a slaughterhouse wastewater treatment plant. J. Environ. Chem. Eng. 2013;1: 453-459.

25. Mees JBR, Gomes SD, Hasan SDM, Gomes BM, Vilas Boas MA. Nitrogen removal in a SBR operated with and without pre-denitrification: Effect of the carbon: Nitrogen ratio and the cycle time. Environ. Technol. 2014;35:115-123.

26. Bohdziewicz J, Sroka E. Integrated system of activated sludge-reverse osmosis in the treatment of the wastewater from the meat industry. Process Biochem. 2005;40:1517-1523.

27. Bustillo-Lecompte CF, Mehrvar M, Quiñones-Bolaños E. Combined anaerobic-aerobic and $\mathrm{UV} / \mathrm{H}_{2} \mathrm{O}_{2}$ processes for the treatment of synthetic slaughterhouse wastewater. J. Environ. Sci. Health A. 2013;48:1122-1135. 